\title{
Impacto de novas edificações na vizinhança: proposta de método para a análise das condições de iluminação natural e de insolação
}

Impact of new buildings in the neighbourhood: proposed method for analysing daylighting and insolation conditions

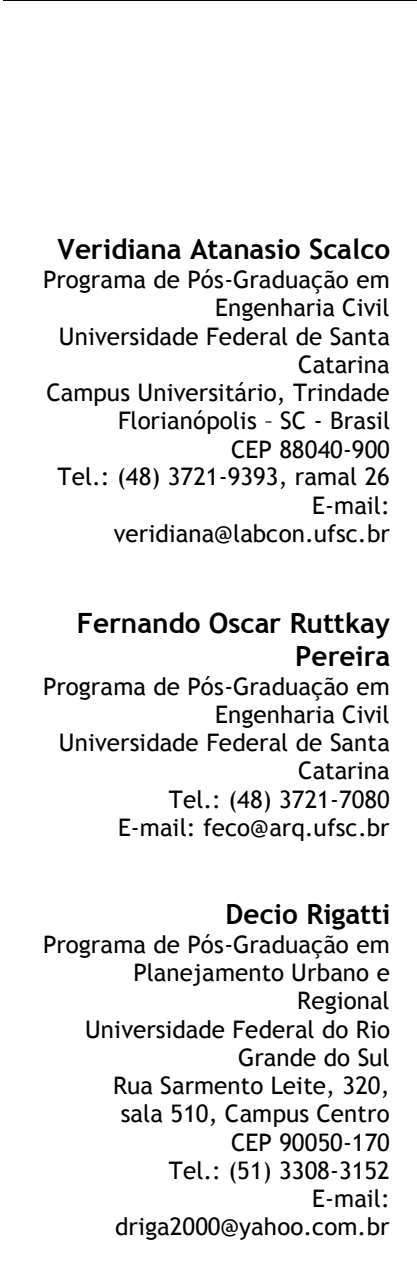

Recebido em 19/02/2010 Aceito em 02/06/2010

\section{Veridiana Atanasio Scalco \\ Fernando Oscar Ruttkay Pereira \\ Decio Rigatti}

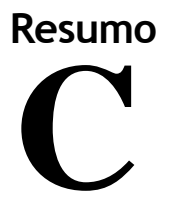

om o crescimento das cidades, aliado à especulação imobiliária, tem-se tornado cada vez mais difícil garantir iluminação natural e insolação de maneira satisfatória nas edificações. Isso se deve principalmente à densificação urbana, determinada por lotes demasiadamente ocupados, e à verticalização acelerada. Com o advento do Estatuto da Cidade, novos instrumentos para esse controle urbano têm sido introduzidos gradativamente por planos diretores de cidades brasileiras, tais como estudos de impacto de vizinhança para determinados empreendimentos. Entretanto, não existem métodos consistentes e padronizados para a análise de alguns dos itens abordados nesses estudos, entre os quais se destacam a iluminação natural e a insolação. Esta pesquisa objetiva o desenvolvimento de um método para a análise do impacto de edificações urbanas em relação às condições mínimas de insolação e de iluminação natural, utilizando como ferramenta a simulação computacional.

Palavras-chave: Impacto de vizinhança. Iluminação natural. Insolação.

\section{Abstract}

The satisfactory admission of daylighting and insolation in buildings has become difficult because of the growth of urban areas, and of the speculative real estate market. This is mainly due to urban densification determined by the intense use of plots and the construction of tall buildings. With the approval of Statute of City, new instruments for urban control have been gradually introduced in the masterplans of Brazilian cities, including the need to undertake neighbourhood impact studies for some projects. However, there are no standardized and consistent methods to analyse some of issues involved in those studies, such as daylighting and insolation. The aim of this research work is to develop a method to analyse the impact of new buildings, considering minimal requirements of insolation and daylighting, by using computational simulation.

Keywords: Neighbourhood impact. Daylighting. Insolation. 


\section{Introdução}

Diferentes fenômenos têm provocado o aumento no número dos habitantes de cidades. Na maioria das vezes, o crescimento da população urbana é motivado por condições favoráveis de diferentes ordens, que, geralmente, estão associadas a uma situação de prosperidade socioeconômica. Com o aumento de habitantes, vegetativo ou não, lança-se, inevitavelmente, um grande desafio às cidades: prover condições mínimas para as pessoas residirem, estudarem, trabalharem e se desenvolverem.

Nesse sentido, o crescimento construtivo ocorre paralelamente, mediante o surgimento de novas edificações urbanas. Dessa forma, de maneira sucessiva, cada nova edificação construída gera impactos no entorno consolidado, entre os quais o acesso aos recursos naturais. A iluminação natural e a insolação são recursos dessa natureza que podem ser modificados com a presença de uma nova edificação. Ambos são provenientes do Sol, mas com características distintas em sua admissão.

Especialmente na última década, passaram-se a observar no Brasil mudanças na legislação referente ao sistema de planejamento das cidades. O Ministério das Cidades aprovou em 2001 a Lei Federal $n^{\circ} 10.257$, denominada Estatuto da Cidade (BRASIL, 2001). A lei consiste em estabelecer normas de ordem pública e interesse social que regulem o uso da propriedade urbana em prol do bem coletivo, da segurança e do bem-estar dos cidadãos, bem como do equilíbrio ambiental. Para atingir tais objetivos, o Estatuto apresenta diversos instrumentos urbanísticos, como o estudo de impacto de vizinhança (EIV). Esse estudo deve ser executado de forma a contemplar os efeitos positivos e negativos do empreendimento ou atividade quanto à qualidade de vida da população residente na área e em suas proximidades. Entre os itens mínimos a serem avaliados encontra-se a iluminação.

Tanto esse quanto os demais itens são apenas descritos pelo Estatuto da Cidade, mas não caracterizados. O único documento acessível que contém informações mais detalhadas é o Estudo de Impacto de Vizinhança, produzido pelo Ministério Público Federal em 2008 (BRASIL, 2008). Nesse documento, o item "iluminação" inclui aspectos relativos à insolação, havendo equívoco no próprio entendimento dos fenômenos que, embora advenham da mesma fonte, são significativamente diferentes: "Trata-se das condições de insolação, radiação e luminosidade preexistentes no local e das possíveis interferências causadas pelo empreendimento no microclima da vizinhança, extrapolando o espaço privado do empreendimento e sua respectiva construção".
A palavra "iluminação", nesse caso, significa, na verdade, iluminação natural e insolação, de acordo com a definição acima. Insolação é a radiação solar térmica responsável pelo calor e apresenta diferentes magnitudes para cada clima, período do ano e horário do dia. Em relação ao conforto térmico humano, em algumas cidades brasileiras, principalmente no Sul do país, a incidência de radiação solar direta é desejável no inverno e indesejável no verão. Além disso, pode-se requerer o máximo possível de horas de incidência dessa radiação para o aquecimento solar de água ou para a geração de energia fotovoltaica.

A luminosidade dependerá das condições de céu e do entorno urbano. As condições de céu modificam a difusão da luz natural do Sol na abóboda celeste. Além disso, a luz natural (direta do Sol e indireta do céu) é modificada pelo ambiente urbano até atingir o ambiente interno, produzindo diferentes níveis de iluminância, a ponto de possibilitar ou não a realização de tarefas visuais do dia a dia.

Após a aprovação do Estatuto da Cidade, os EIVs têm sido gradativamente incorporados aos Planos Diretores das cidades. Um dos maiores problemas verificados atualmente é a falta de padronização e consistência dos métodos empregados no Brasil para a avaliação dos impactos relativos aos itens mencionados na lei. Além disso, os estudos já realizados consideram o termo "iluminação" como insolação, conforme será descrito a seguir. Tanto na literatura específica da área quanto em estudos de impacto internacionais - ainda que se adaptem às realidades climáticas locais e, consequentemente, requeiram diferentes demandas de recursos naturais -, identificam-se métodos que são consensuais na literatura internacional.

Visando aprofundar essas questões, esta pesquisa desenvolver um método para a análise do impacto na vizinhança de novas edificações em relação ao acesso à iluminação natural e à insolação. Trata-se de uma questão atual e pertinente, à medida que o próprio poder público considera a iluminação natural e insolação como importante quesito na configuração de futuras edificações.

\section{Métodos para a avaliação da iluminação natural e insolação em estudos de impacto de vizinhança}

Os métodos para a avaliação da iluminação natural e insolação em ambientes urbanos são 
caracterizados por parâmetros de desempenho e técnicas específicas. Visando ao embasamento dessa proposta de método, pesquisou-se a aplicação desses itens tanto na literatura específica quanto em estudos de impacto de vizinhança já realizados, conforme descrito a seguir.

\section{Métodos verificados na literatura específica}

Nesta pesquisa foram considerados apenas os parâmetros e técnicas que consideram a parcela incidente da iluminação natural e insolação. Entretanto, existem outros que consideram também as parcelas referentes à reflexão das superfícies.

\section{Parâmetros de desempenho}

A literatura específica não apresenta métodos direcionados à avaliação de impactos de vizinhança, entretanto os parâmetros e técnicas apresentados são passíveis de adaptações para essa finalidade.

Os parâmetros de desempenho empregados em pesquisas científicas estão listados no Quadro1, ao lado dos principais autores pesquisados.

\section{Iluminação}

Existem aspectos positivos e limitações a serem considerados sobre esses parâmetros. Em relação à iluminação natural, Alucci (1986) e Moretti (1993) utilizam a probabilidade de ocorrência da iluminância sobre o plano horizontal. O nível de iluminância deve ser de 150 lux em $80 \%$ do ano. Apesar de a iluminância ser o parâmetro referencial que originou outros, não se apresenta como o mais adequado para a avaliação do ambiente urbano. Isso ocorre em virtude da disponibilidade das fontes (Sol e céu), que varia consideravelmente ao longo do dia e do ano.

Logo, o fator de luz diurna (FLD), caracterizado pela relação em porcentagem da iluminância em determinado ponto interno e a iluminância em um plano horizontal externo, apresenta-se como um parâmetro bastante adequado, pelo fato de considerar a parcela incidente de iluminação natural de acordo com a disponibilidade de luz. Além disso, o referido parâmetro considera o céu encoberto, ou seja, a pior condição de disponibilidade de luz natural direta, a qual é responsável pela menor contribuição de iluminação nos ambientes internos. Nesse caso, garantindo-se uma porcentagem mínima dessa fonte, será garantida a iluminação adequada nas demais variações de céu.

O FLDV foi utilizado como parâmetro-base para a confecção de outros, como a área de visão desobstruída (AVD). Ambos consideram as porções obstruídas e desobstruídas para a aferição da iluminação natural incidente. Em relação à AVD, faz-se necessário destacar a pesquisa realizada por $\mathrm{Ng}$ (2003). O autor utilizou entrevistas e simulações para a determinação de um valor mínimo de FLDV que satisfizesse os usuários residentes em área urbana. Como esta é a única fonte de pesquisa dessa natureza, considerase que os valores encontrados pelo autor podem variar por razões socioculturais e por fatores climáticos, como salienta o próprio autor.

\begin{tabular}{|c|c|c|}
\hline \multicolumn{2}{|r|}{ Parâmetro de desempenho } & $\begin{array}{c}\text { Autores } \\
\end{array}$ \\
\hline \multirow{7}{*}{ 导 } & Probabilidade de ocorrência de iluminâncias & ALUCCI, 1986; MORETTI, 1993 \\
\hline & $\begin{array}{l}\text { FLDV - Fator de Luz Diurna } \\
\text { Vertical/Componente Celeste Vertical }\end{array}$ & NG, 2003, 2005; TREGENZA, 2001 \\
\hline & Indicadores de Altura Admissível & $\begin{array}{l}\text { HOPKINSON, PETHERBRIDGE, } \\
\text { LONGMORE, 1966; ROBBINS, } 1986\end{array}$ \\
\hline & Linha de "Não" Visão do Céu & LITTLEFAIR, 1991 \\
\hline & AVD - Área de Visão Desobstruída & NG, 2003 \\
\hline & JCP - Janela de Céu Preferível & LEDER, 2007 \\
\hline & FVC - Fator de Visão do Céu & CHENG et al., 2006 \\
\hline \multirow{4}{*}{ 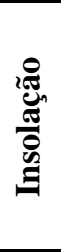 } & Horas de Sol & $\begin{array}{l}\text { HMSO, 1982; KNOWLES, 1981; NE'EMAN; } \\
\text { HOPKINSON, 1976; OBOLENSKY; KORZIN, } \\
\text { 1982; TREGENZA, } 1993\end{array}$ \\
\hline & Disponibilidade da Luz Solar & NE'EMAN; LIGHT, 1975 \\
\hline & Radiação Solar & CAPELUTO et al., 2006; LITTLEFAIR, 1991 \\
\hline & RP - Radiação Ponderada & AROZTEGUI, 1980 \\
\hline
\end{tabular}

Quadro 1 - Parâmetros de desempenho e principais autores pesquisados 
A AVD também é um parâmetro de desempenho que utiliza como base o FLDV. Essa área é traçada por meio de um cone de visão no plano horizontal posicionado nas janelas dos edifícios, traçando-se 50 graus à esquerda e à direita a partir do centro da janela analisada. O comprimento do cone tem a mesma dimensão da altura do edifício até a janela analisada. Alguns edifícios da vizinhança poderão estar parcial ou totalmente dentro do cone, obstruindo a "visão" de uma parcela do céu. O restante da parcela constitui-se na AVD propriamente dita.

A AVD, além de utilizar o FLDV como parâmetrobase, fundamenta-se nos indicadores de altura admissíveis. O princípio desses indicadores é prover iluminação adequada na fachada mediante limitações na largura e na altura angulares dos edifícios obstrutivos, ou seja, através de uma zona angular. Os indicadores foram pioneiros na década de 1960 por considerar não apenas ângulos limitando a altura dos edifícios, mas também ângulos horizontais controlando o espaçamento entre as edificações (HOPKINSON; PETHERBRIDGE; LONGMORE, 1966; ROBBINS, 1986). Mais tarde, Littlefair (1991) propôs a linha de "não visão" do céu, que utiliza o critério angular simples horizontal. $\mathrm{O}$ valor desse ângulo varia de acordo com a latitude; para Londres, ele deve ser de, no máximo, 25 graus.

Apesar de Hopkinson, Petherbridge e Longmore (1966) e Littlefair (1991), atualmente existem formas mais avançadas de determinar uma zona angular desobstruída, como se verifica no FLDV, na AVD e na janela de céu preferível (JCP).

A JCP, desenvolvida por Leder (2007), consiste em uma porção do céu limitada por ângulos de azimute e altura solar, ou seja, uma zona angular onde o potencial da iluminação natural em ambientes internos é máximo. Consequentemente, quanto maior a desobstrução da JCP, maior será o aproveitamento desse potencial.

O último parâmetro de avaliação da iluminação natural pesquisado refere-se ao fator de visão do céu (FVC). Este se constitui de apenas uma porcentagem de visibilidade do céu e é geralmente associado a outros parâmetros. Segundo Lindberg et al. (2003), o FVC é usado frequentemente para descrever as variações de temperatura da geometria urbana e intraurbana.

\section{Insolação}

Em relação aos parâmetros concernentes à insolação, a utilização de apenas um número de horas de sol nas fachadas pode ser questionável. Assim como o FLDV, o número de horas também pode ter implicações socioculturais. Entretanto, é reconhecido que existem necessidades psicofisiológicas humanas associadas a esse parâmetro, além da grande importância que o aquecimento solar passivo possui em algumas cidades e períodos do ano devido às baixas temperaturas do ar.

Já em relação à radiação solar, é importante conhecer os requisitos térmicos da edificação em função do clima, para atendimento de condições de conforto humano de cada período, dia e hora do ano, e não somente sua magnitude. A radiação ponderada proposta por Aroztegui (1980) indica essa necessidade por meio de valores de desejabilidade e de indesejabilidade, utilizando o diagrama de trajetórias associado. Dessa forma, as horas de sol não são consideradas apenas por sua quantidade.

A disponibilidade de luz solar também se apresenta como mais um dado horário do diagrama de trajetórias solares sobre a probabilidade de o Sol estar brilhando, assim como a radiação solar ponderada.

\section{Técnicas específicas}

As técnicas que consideram a parcela incidente da iluminação natural e insolação podem ser divididas em dois grupos: visibilidade/obstrução e estudos de sombras.

O primeiro grupo refere-se à técnica de representação da visibilidade/obstrução do entorno de determinado ponto de análise (máscara), utilizada tanto para iluminação natural quanto para insolação. Esse grupo é subdividido em duas partes. A primeira delas é composta do critério angular simples, zona angular e envelope solar.

O critério angular simples é determinado por um ângulo vertical ou horizontal. Como exemplo temse a utilização de um ângulo horizontal para a determinação da AVD proposta por $\mathrm{Ng}$ (2003). A zona angular, exemplificada pela JCP (Leder, 2007) e os indicadores de altura admissíveis (HOPKINSON, PETHERBRIDGE, LONGMORE, 1966), é composta de ângulos verticais e horizontais. Já o envelope solar é composto de três ou mais ângulos verticais, dependendo do número de arestas do lote considerado. Ele pode ser verificado em diferentes aplicações, como, por exemplo, nas proposições de Knowles (1981) e de Pereira, Silva e Turkienikz (2001).

O critério angular simples e a zona angular são aplicados no edifício de interesse para seu próprio benefício; já o envelope solar limita a obstrução no terreno de forma a não violar o acesso à iluminação natural e insolação das edificações contíguas a ele.

A segunda parte refere-se aos diagramas de trajetória. Em sua aplicação mais simples, pode-se 
avaliar a influência das obstruções urbanas no acesso à insolação em um ponto de análise. Já os diagramas de trajetória podem estar associados a parâmetros de iluminação natural ou insolação. Um exemplo é a radiação ponderada, que indica o valor de desejabilidade da radiação solar para cada hora proposto por Aroztegui (1980).

Os estudos de sombra - segundo grupo - baseiamse na determinação de um dia e hora do ano ou mais, para verificação das sombras na vizinhança, ou seja, são aplicáveis apenas para análises de insolação.

Os dois grupos de técnicas citados são utilizados para avaliar diferentes parâmetros de iluminação natural e insolação. Além disso, a utilização de todas as técnicas pode ser feita tanto de maneira computacional quanto de maneira gráfica.

\section{Programas computacionais}

A maioria dos parâmetros de desempenho e técnicas específicas relatados neste artigo pode ser aplicada de maneira gráfica ou por meio de programas computacionais. A utilização destes últimos confere precisão e agilidade à aquisição dos resultados.

Existem diversos programas computacionais que podem ser usados para a avaliação da iluminação e/ou insolação no ambiente urbano, entre os quais Apolux, Cityzoom, Ecotect, Desktop Radiance, IES Virtual Environment e SunTools Plug-in Sketchup.

Nesta pesquisa utilizou-se o programa Apolux, desenvolvido no Laboratório de Conforto Ambiental da Universidade Federal de Santa Catarina, que utiliza como referência conceitual o modelo vetorial esférico desenvolvido por Claro (1998) em seu doutoramento.

O programa realiza os cálculos de iluminação natural a partir da utilização de dois módulos. O módulo Fractal prepara um arquivo de desenho no formato *.dxf, e o Foton processa os cálculos. Sua principal capacidade está em processar materiais opacos difusos, opacos especulares, transmissores difusos e transmissores especulares. Os dados gerados pelo programa podem ser visualizados por meio de imagens semirrealistas, máscaras de visibilidade/obstrução, gráficos de iluminância, luminância e de fator de luz diurna. Além disso, planilhas numéricas com vários dados para pósprocessamento podem ser obtidas.

\section{Métodos verificados em estudos de impacto de vizinhança}

A pesquisa por parâmetros e técnicas em estudos de impacto nacionais e internacionais registrou consideráveis discrepâncias na forma de avaliar os impactos, como se pode observar a seguir.

\section{Estudos nacionais}

A pesquisa por estudos de impacto de vizinhança nacionais foi realizada in loco (Instituto de Planejamento de Florianópolis) e por intermédio de prefeituras municiais que disponibilizaram tais estudos em suas páginas da internet. Foram encontrados 66 estudos distribuídos entre as cidades de Bragança Paulista, SP, Niterói, RJ, Araucária, PR, e Florianópolis, SC.

Trinta e três justificaram a ausência de impactos em virtude de o projeto estar em conformidade com os índices mínimos de iluminação definidos no regime urbanístico da cidade.

Alguns estudos não demonstram a análise dos impactos, mas concluíram a respeito. Onze garantem que as zonas de sombra geradas pelas edificações ocorrem apenas na área do empreendimento. Outros dois estudos asseguram que a vizinhança não será prejudicada em termos de iluminação, já que o projeto se apropria da declividade da topografia da cidade para esse objetivo.

Surpreendentemente, treze estudos apresentam conclusões apenas sobre a própria edificação, e não sobre sua vizinhança. Doze destes relatam que o empreendimento tem grande luminosidade. Além disso, afirmam que ele não produz zonas de sombras. Um dos estudos que relata sobre a própria edificação também declara que existem janelas e telhas translúcidas para auxiliar na iluminação.

Apenas sete dos estudos realizados em Florianópolis e Niterói utilizaram técnicas específicas. Em todos estes utilizou-se a técnica de estudos de sombras, ou seja, considerou-se apenas a insolação. Já em relação aos parâmetros de desempenho possíveis para a avaliação desse fenômeno, como, por exemplo, determinado número de horas de sol nas fachadas nos meses do inverno, nenhum dos estudos os adotou para auxiliar na identificação dos impactos. Nesses casos, as avaliações deles foram feitas apenas de maneira visual.

\section{Estudos internacionais}

A maioria dos estudos de impacto de vizinhança internacionais pesquisados apresenta análises relativas à iluminação natural e à insolação. As duas abordagens apresentam-se divididas nas seções a seguir. 


\section{Iluminação natural}

A pesquisa por estudos internacionais foi realizada pela internet. Por esse motivo, dependeu da disponibilidade deles em sites correlatos, como, por exemplo, prefeituras municipais, bibliotecas públicas ou associações de bairro. Em relação à iluminação natural, dois métodos foram encontrados. O método do Building Research Establishment (BRE), da Inglaterra, foi empregado em quarenta e quatro dos estudos. Já o método americano Boston Redevelopment Authority Daylight Analysis (BRADA) foi verificado em seis estudos.

O método BRE, desenvolvido para a Inglaterra, descreve procedimentos para a avaliação da iluminação natural e insolação empregando como base a publicação de Littlefair (1991) "Site layout planning for daylight and sunlight: a guide to good practice". Este é sem dúvida o método mais consistente de todos os internacionais verificados. A avaliação do acesso à iluminação natural na vizinhança possui quatro etapas nesse método. De acordo com o resultado da primeira etapa, será necessário ou não efetuar a segunda, e assim sucessivamente. A primeira delas refere-se à verificação da obstrução vertical, traçando-se uma linha na fachada a $2 \mathrm{~m}$ do solo até a cobertura do edifício vizinho, a qual não deve exceder 25 graus. A segunda verificação deve ser efetuada em relação ao FLDV; as janelas deverão apresentar no mínimo $27 \%$ desse parâmetro. Se a componente não atingir esse valor, verifica-se o mesmo para a situação basal, ou seja, a situação anterior à proposta de projeto. A contribuição da iluminação do céu será prejudicada se a componente não atingir este valor e se o valor da proposta for 0,8 vez menor que o valor basal. Como última verificação, pode-se utilizar tanto o FLD quanto a linha de "não" visão do céu do ambiente interno na situação anterior e posterior à proposta de projeto, ambos no plano de trabalho. A média do FLDV não pode ser menor que $1 \%$ para quartos, $1,5 \%$ para salas de estar e $2 \%$ para cozinhas. Já a área do plano de trabalho que "enxerga" o céu delimitado pela linha de "não" visão do céu - traçada verticalmente a partir da verga da janela até a obstrução externa vertical passando pelo plano de trabalho - não pode ser menor que $20 \%$ da área anterior à proposta de projeto.

Além do método proposto pelo BRE, seis estudos utilizaram o método BRADA. De acordo com este método, o fator de visão de céu deve ser verificado em pontos situados no eixo das ruas adjacentes ao empreendimento. Em todos os estudos é verificada apenas a descrição do resultado de maneira visual, como no caso dos estudos brasileiros, não se definindo um parâmetro máximo de obstrução para a determinação dos impactos.

\section{Insolação}

Em relação à insolação, encontraram-se trinta e seis estudos citando o método do BRE, cinco citando o método da The California Environmental Quality Act - Thresholds Guide (CEQA) e dois referindo-se ao método australiano da Residencial Design Amenity - Solar Analysis Technique (COX/ATA).

O método BRE para insolação possui apenas uma etapa de avaliação, que utiliza como parâmetro dados de probabilidade anual de horas de sol. Os pontos das fachadas localizados no centro das janelas voltadas para o norte geográfico deverão apresentar mais de $25 \%$ das horas de sol prováveis anuais. Além disso, em 5\% destas horas durante o inverno e solstícios o valor encontrado na situação de projeto não deverá ser menor que $80 \%$ do valor basal. O valor basal é o valor encontrado na análise anterior à proposta de projeto para a vizinhança.

O método para a análise da insolação contido no CEQA foi desenvolvido em Los Angeles. De acordo com o CEQA, o impacto das sombras será considerado significativo se a vizinhança for sombreada pela proposta de projeto por mais de três horas entre as $9 \mathrm{~h}$ e as $15 \mathrm{~h}$ entre o final de outubro e o início de abril, ou por mais de quatro horas entre as $9 \mathrm{~h}$ e as $17 \mathrm{~h}$ entre o início de abril e o final de outubro.

Dois estudos da Austrália citaram o método COX/ATA, desenvolvido por uma empresa que realiza consultorias na área. Como critério para a verificação dos impactos, pelo menos $70 \%$ dos apartamentos da vizinhança deverão receber insolação por no mínimo duas horas no solstício de inverno.

Todos os métodos citados consideram números de horas de insolação para a determinação dos impactos. A maioria deles visa garantir essas horas no período do inverno, quando a necessidade de radiação solar para aquecimento é necessário devido às baixas temperaturas naqueles países.

\section{Proposta de método para a determinação dos impactos de novas edificações na vizinhança}

A proposta de método para a determinação de impactos de novas edificações na vizinhança consistiu na definição de parâmetros de desempenho e técnica específica para a análise da 
iluminação natural e insolação e procedimentos de aplicação desenvolvidos com base na revisão bibliográfica apresentada brevemente neste artigo.

\section{Parâmetros de desempenho e técnica específica adotados}

Iluminação natural

\section{Parâmetro FLDV}

O principal parâmetro de desempenho escolhido para a avaliação da iluminação natural foi o fator de luz diurna vertical (FLDV). Para a determinação dos impactos, utilizou-se o valor de $10 \%$ como mínimo, determinado por Tregenza (2001). Segundo o autor, esse valor garante que ambientes internos possuam 0,5\% de FLD como média, desde que suas aberturas possuam área equivalente ou superior a $1 / 25$ da área do piso. $O$ FLDV apresenta-se como um parâmetro adequado, pois considera a parcela incidente de iluminação natural de acordo com a disponibilidade de luz em um plano horizontal externo.

\section{Parâmetro complementar JCP}

A janela de céu preferível (JCP) (LEDER, 2007) consiste em uma porção do céu limitada por ângulos de azimute e altura solar, ou seja, uma zona angular, onde o potencial da iluminação natural em ambientes internos é máximo. Consequentemente, quanto maior a desobstrução da JCP, maior será o aproveitamento desse potencial.

Para o estudo de impacto de vizinhança, importará o valor total de FLDV, derivado de toda a porção visível do céu. Entretanto, como consideração complementar, determina-se qual quantidade da porção mais favorável do céu para iluminação (JCP) será visível pelos pontos de análise localizados nas fachadas.

\section{Insolação}

\section{Parâmetro Radiação Ponderada}

Em relação à insolação, utilizaram-se dois parâmetros. O primeiro deles refere-se ao conceito de radiação ponderada (RP), desenvolvida por Aroztegui (1980). Segundo o autor, a satisfação ou insatisfação humana produzida pela radiação solar incidente pode ser representada por um sistema de ponderação da radiação solar como a diferença entre a temperatura externa do ar e a temperatura neutra, considerando uma série de critérios climáticos, psicofisiológicos e de representação geométrica. Se a temperatura do ar de determinada localidade for maior que a neutra, a radiação ponderada será considerada negativa, ou seja, a insolação será indesejável. Se positiva, a insolação será desejável. Dessa forma, será possível avaliar a magnitude dessa radiação durante todo o ano, obtendo-se o balanço dos valores horários mediante a soma deles. Como estratégia utiliza-se a busca por balanços positivos durante o ano. A análise de balanços das radiações ponderadas pode indicar condições de maior ou menor exposição de radiações desejáveis ou indesejáveis. No caso de uma proposta de projeto para a vizinhança, este pode sofrer alterações em sua implantação, por exemplo, para que as radiações indesejáveis sejam minimizadas.

Entretanto, a avaliação da insolação por meio do balanço anual de radiação ponderada não poderá ser utilizada para todas as cidades brasileiras. Em algumas regiões do Brasil, as temperaturas do ar uma das bases do fundamento das radiações ponderadas - são altas, o que faz com que essa radiação seja indesejável na maior parte do ano. Portanto, nesses casos, a avaliação da iluminação natural é mais restritiva em termos de obstrução urbana. Já outras regiões, como as zonas 1, 2 e 3 do mapeamento bioclimático brasileiro (Figura 1), possuem maiores variações nas temperaturas anuais. $\mathrm{O}$ aquecimento solar passivo, principalmente nos meses do inverno, faz-se necessário como estratégia bioclimática das edificações localizadas nessas zonas. O balanço positivo garantirá a predominância de radiações desejáveis, que auxiliarão nesse aquecimento.

\section{Técnica específica}

A técnica utilizada no método considera apenas a parcela incidente da iluminação natural e insolação através dos parâmetros já descritos. Para tanto, utilizou-se a representação gráfica de visibilidade/obstrução da vizinhança em diagrama de trajetória solar associado, com aporte computacional. As horas de insolação poderão ser verificadas visualmente no próprio diagrama, e a associação se dará em função dos demais parâmetros: radiação ponderada, FLDV e JCP.

\section{Procedimentos de aplicação}

Os procedimentos de aplicação do método proposto estão divididos em cinco etapas, conforme descrito a seguir. 


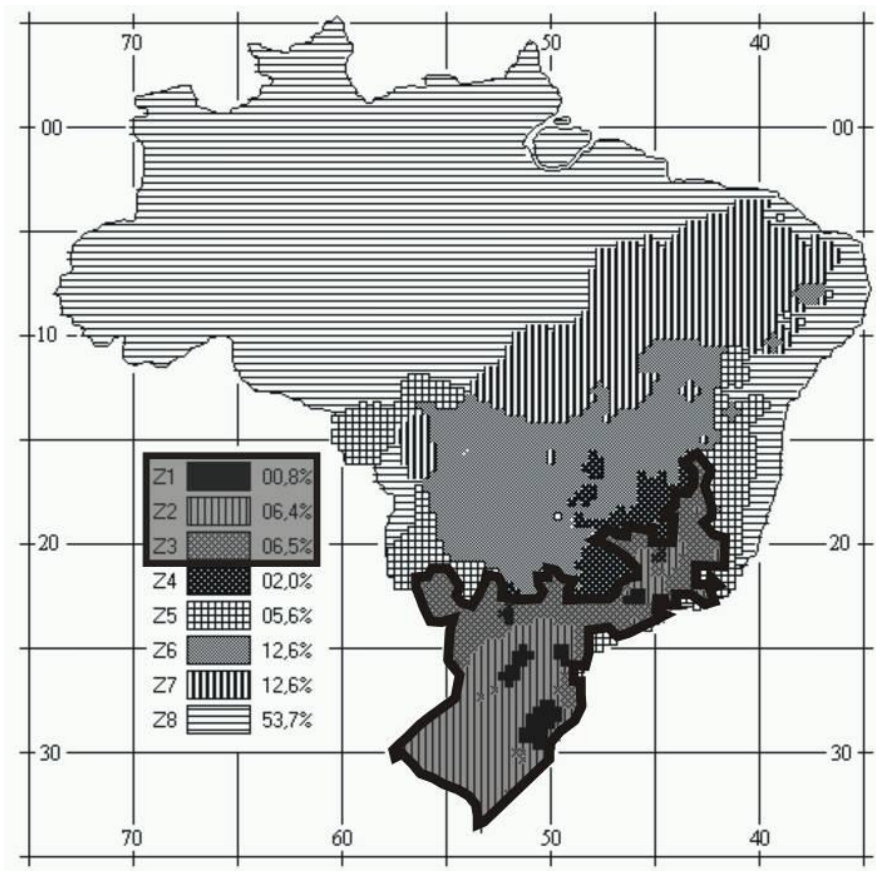

Fonte: ABNT (2005).

Figura 1 - Delimitação das três zonas bioclimáticas onde a avaliação dos impactos relativos à insolação deve ser realizada

\section{Delimitação da área de abrangência dos impactos}

A área de abrangência dos impactos refere-se à área da vizinhança máxima ao redor do objeto de impacto (OI) que será influenciada. Dessa forma, todas as edificações que pertencerem a essa área deverão ser analisadas. Sua delimitação considera dois aspectos: a obstrução do céu e a topografia. A primeira delas refere-se ao critério de obstrução utilizado para determinar o menor ângulo vertical da JCP: $15^{\circ}$. Segundo Leder (2007), esse valor foi adotado como limite por considerar-se que, usualmente, essa altura apresenta-se obstruída, devido ao entorno natural ou construído. Assim, um ponto na vizinhança a $1 \mathrm{~m}$ do solo - altura de referência em relação à localização aproximada das aberturas no pavimento térreo - também não "enxergará" o OI se este estiver obstruindo até $15^{\circ}$ de altura angular medidos a partir do referido ponto. Partindo-se desse princípio, encontra-se o centro geométrico do OI para a determinação de oito retas auxiliares orientadas a N, NE, E, SE, S, SO, O e NO. Para cada orientação, calcula-se o raio de abrangência dos impactos por meio de trigonometria básica, considerando-se a distância a partir da borda do edifício (exemplo para a direção norte na Figura 2).

Em seguida, os oito raios calculados devem ser corrigidos em relação à topografia, em virtude da diferença de cota entre os pontos nas extremidades da vizinhança e o OI. Se o OI estiver acima da cota do ponto da vizinhança, seu raio de abrangência será maior que o calculado. Então, soma-se a diferença de cota na altura do edifício para calcular a tangente (janela 3 da Figura 3). Entretanto, se o OI estiver localizado abaixo da cota do ponto da vizinhança, seu raio de abrangência será menor que o calculado, pois os valores das cotas serão subtraídos (janela 1 da Figura 3).

Por fim, a área de abrangência é traçada unindo-se os pontos da vizinhança através de arcos tangentes (Figura 4a). Os procedimentos exemplificados anteriormente, nas Figuras 3a e 3b, referem-se a um OI contendo apenas um bloco ou módulo construído. Entretanto, eles poderão ter mais módulos, inclusive com diferentes alturas. Nesse caso, para cada módulo, os procedimentos deverão ser realizados de maneira separada. A área de abrangência resultante dos módulos será a soma delas (Figura 4b).

\section{Levantamento de campo}

O levantamento de campo consiste na atualização do cadastro aerofotogramétrico fornecido pela prefeitura municipal, pois muitas vezes novas edificações não estão presentes neste. Além disso, deve-se realizar a verificação das alturas das edificações in loco. 


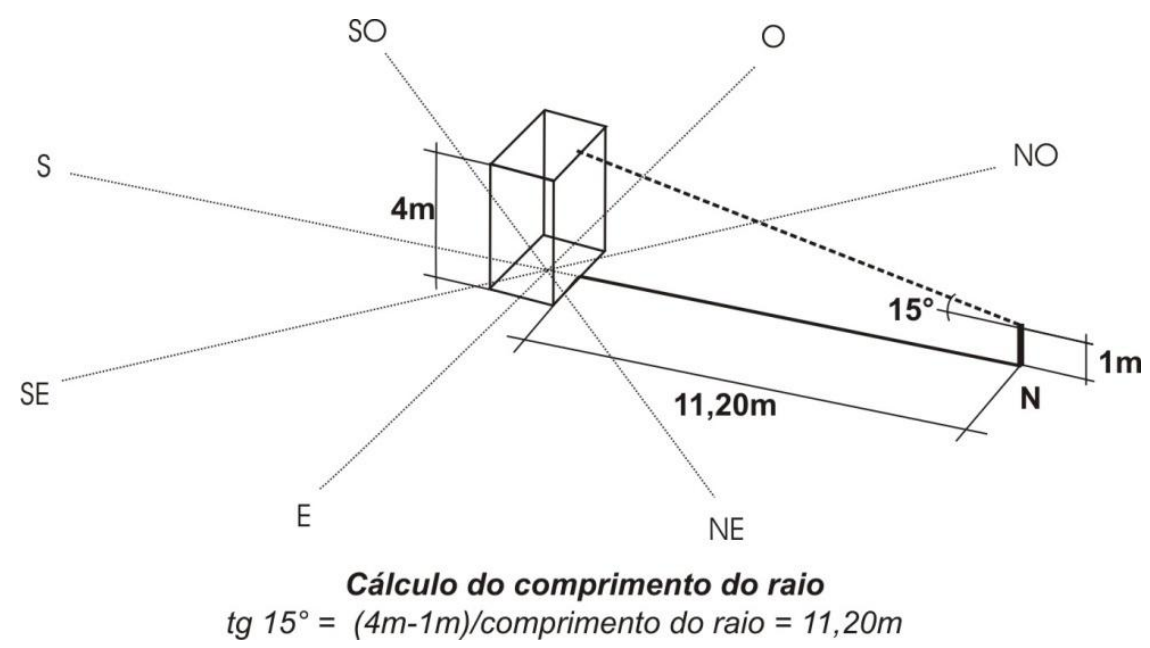

Figura 2 - Exemplo de cálculo do raio da direção norte pelo critério de obstrução da JCP

Dados:

\section{Correção do comprimento dos raios:}

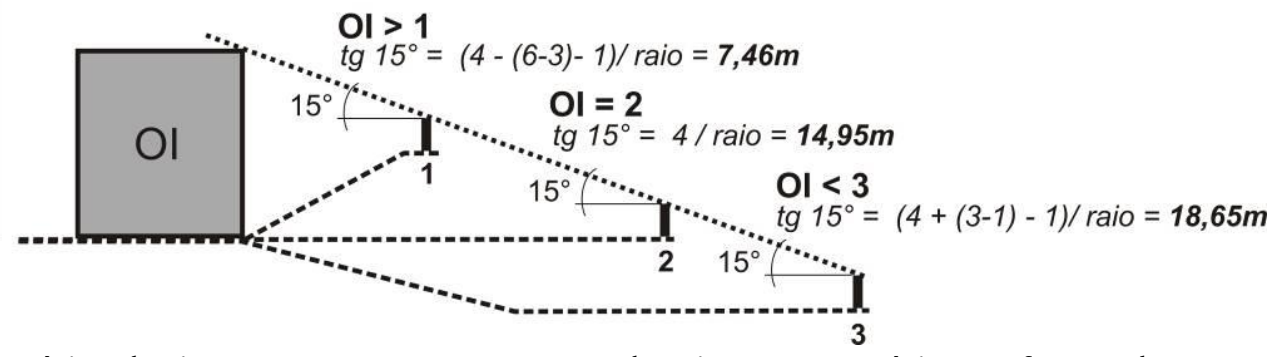

Figura 3 - Corte esquemático de situações em que as correções do raio são necessárias em função das diferenças de cota entre o Ol e a vizinhança

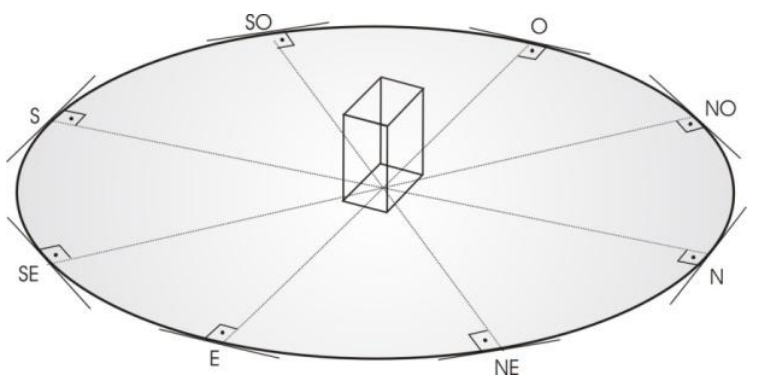

(a)

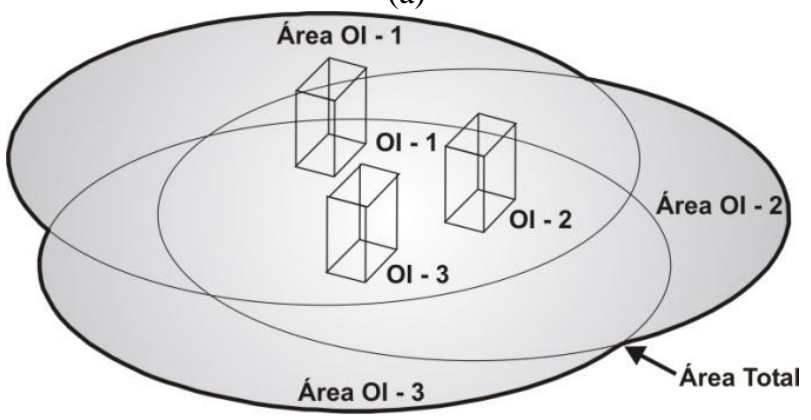

(b)

Figura 4 - Área de abrangência a partir de arcos tangentes, contendo diferentes módulos 


\section{Modelagem}

A modelagem da área de abrangência - base topográfica e edificações - deve realizada em programas do tipo CAD, utilizando-se sólidos. Para cada edifício da vizinhança, identificam-se em planta quais de suas fachadas "enxergam" o OI. Esse procedimento é necessário para poupar a análise das fachadas que não serão influenciadas no impacto.

Nas fachadas identificadas, é tomado um ponto no centro de cada pavimento. Esse ponto é representado no programa Apolux por um pequeno triângulo. $\mathrm{O}$ valor de referência para a avaliação é tomado a partir do vértice superior do triângulo. As informações dos demais vértices servirão somente para a aferição dos valores.

Ao final da modelagem, dois arquivos serão criados e salvos em formato *.dxf, contendo o terreno com e sem a presença do OI, ambos necessários para a análise dos impactos de vizinhança. Esses arquivos devem ter seus sólidos transformados em faces, para o reconhecimento do programa Apolux.

\section{Simulações}

Os procedimentos de simulação devem ser realizados separadamente para cada um dos arquivos gerados na modelagem. Inicialmente, o arquivo *.dxf é importado para o modo Fractal do programa Apolux. Nesse modo, as superfícies do arquivo são fragmentadas para que sejam visualizadas no modo seguinte do programa, após a conversão do arquivo para o formato *.pjt. No modo Fóton, faz-se necessário informar quais superfícies serão consideradas planos de análise, as quais deverão estar separadas em um layers diferentes dos demais elementos modelados.

Após esse processo, as máscaras de cada vértice dos planos de análise são obtidas juntamente com seus arquivos, em formato *.csv, contendo os dados numéricos dos parâmetros. $\mathrm{O}$ primeiro formato de dados permite a visualização dos resultados. Já a segunda forma viabiliza a tabulação deles; do contrário seria necessária a verificação máscara a máscara para cada ponto das fachadas da vizinhança.

\section{Avaliação dos impactos}

Com os arquivos em formato *.csv com e sem a presença do OI, inicia-se a análise dos impactos propriamente dita. Cada edifício terá um número " $x$ " de pontos, que possuirão diferentes tipos de impactos para cada um dos parâmetros de análise. Esses impactos poderão ser neutros, positivos ou negativos (Quadro 2). O impacto será considerado neutro se as situações anterior e posterior ao OI forem as mesmas em relação aos valores mínimos, ou seja, ocorrerá se os valores de um parâmetro analisado estiverem abaixo do mínimo requerido ou maior ou igual nas duas situações. Já para que o impacto seja considerado positivo, a situação anterior ao OI não deverá atingir o valor mínimo requerido, e com o OI esse valor deverá ser maior ou igual. No caso de impacto negativo, o valor sem o OI será maior ou igual ao mínimo, e com o OI, menor. É importante destacar que, no caso da iluminação natural, o impacto sempre será neutro ou negativo, pois necessariamente o aumento na obstrução causará redução e FLDV. Já no caso da RP, não será considerado impacto positivo se o OI obstruir radiações indesejáveis. Nesse sentido, o resultado do impacto será neutro, ou seja, não haverá uma piora das condições de insolação em virtude da obstrução do OI. Essa obstrução não deve ser considerada uma melhoria das condições de insolação da edificação impactada.

Os impactos classificados inicialmente como neutros devem ser avaliados de maneira mais detalhada, de acordo com sua suscetibilidade (Quadro 3), pois, na verdade, haverá uma redução ou aumento em relação ao valor anterior à presença do OI. Se houver uma redução de até $20 \%$, o impacto continuará sendo neutro; entretanto, se essa porcentagem for maior, o impacto passará a ser considerado negativo. Havendo um aumento de qualquer magnitude, esse impacto será considerado positivo. A avaliação da suscetibilidade é verificada nos estudos de impacto de vizinhança que utilizam o método BRE.

\section{Aplicação do método em um cenário urbano}

A aplicação do método proposto foi realizada em Porto Alegre, para avaliar o impacto de uma edificação com dezoito pavimentos localizada em uma vizinhança que possui $90 \%$ das edificações com um a quatro pavimentos. A área de abrangência foi dividida em quatro subáreas identificadas por anéis concêntricos e pelas cores das edificações em tons variando de vermelho a amarelo -, e o impacto foi verificado apenas para a maior edificação em altura de cada área dividida (Figura 5a), visando à verificação dos impactos nos diferentes pavimentos. Em seguida, realizou-se a mesma verificação da vizinhança com a ocupação máxima proposta pelo plano diretor vigente (Figura 5b) 


\begin{tabular}{|c|c|c|}
\hline Impacto & Vizinhança sem o OI & Vizinhança com o OI \\
\hline Impacto positivo & Valor $<$ mínimo requerido & Valor $\geq$ mínimo requerido \\
\hline Impacto negativo & Valor $\geq$ mínimo requerido & Valor $<$ mínimo requerido \\
\hline \multirow{2}{*}{ Impacto neutro } & Valor $<$ mínimo requerido & Valor $<$ mínimo requerido \\
\cline { 2 - 3 } & Valor $\geq$ mínimo requerido & Valor $\geq$ mínimo requerido \\
\hline
\end{tabular}

Quadro 2 - Tipos de impactos identificados a partir da comparação entre os valores de parâmetros

\begin{tabular}{|l|l|}
\hline Suscetibilidade & Relação entre a proposta e a condição-base \\
\hline Benefício considerável & Relação de aumento $>1,3$ da condição-base \\
\hline Benefício moderado & Relação de aumento $<1,3$ e $\geq 1,1$ da condição-base \\
\hline Leve benefício & Relação de aumento $<1,1$ e $\geq 1,0$ da condição-base \\
\hline Insignificante & Relação de redução $<1,0$ e $\geq 0,8$ da condição-base \\
\hline Leve adversidade & Relação de redução $<0,8$ e $\geq 0,7$ da condição-base \\
\hline Adversidade moderada & Relação de redução $<0,7$ e $\geq 0,6$ da condição-base \\
\hline Adversidade considerável & Relação de redução $<0,6$ da condição-base \\
\hline
\end{tabular}

Fonte: Driver (2008).

Quadro 3 - Critério de suscetibilidade dos impactos

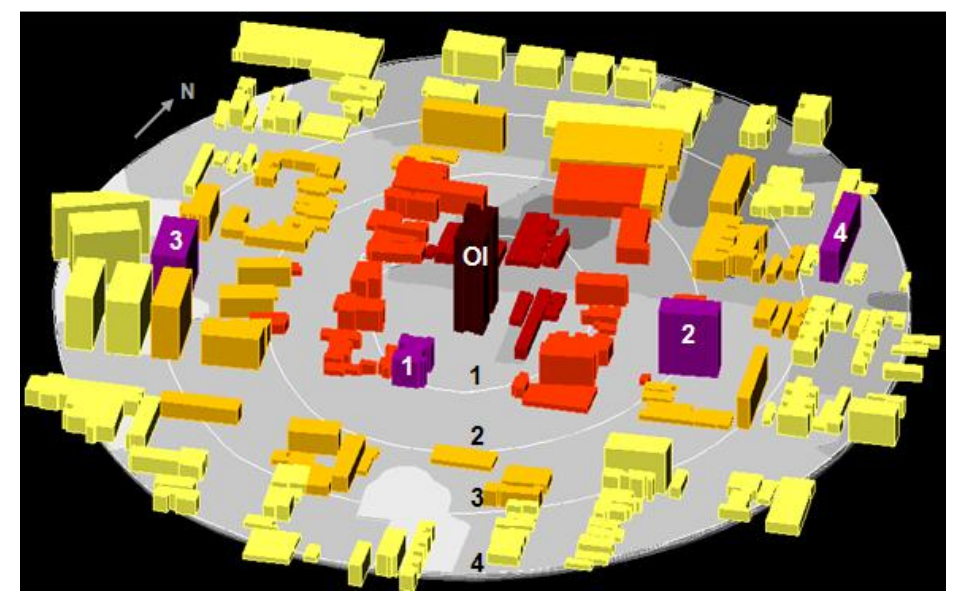

(a)

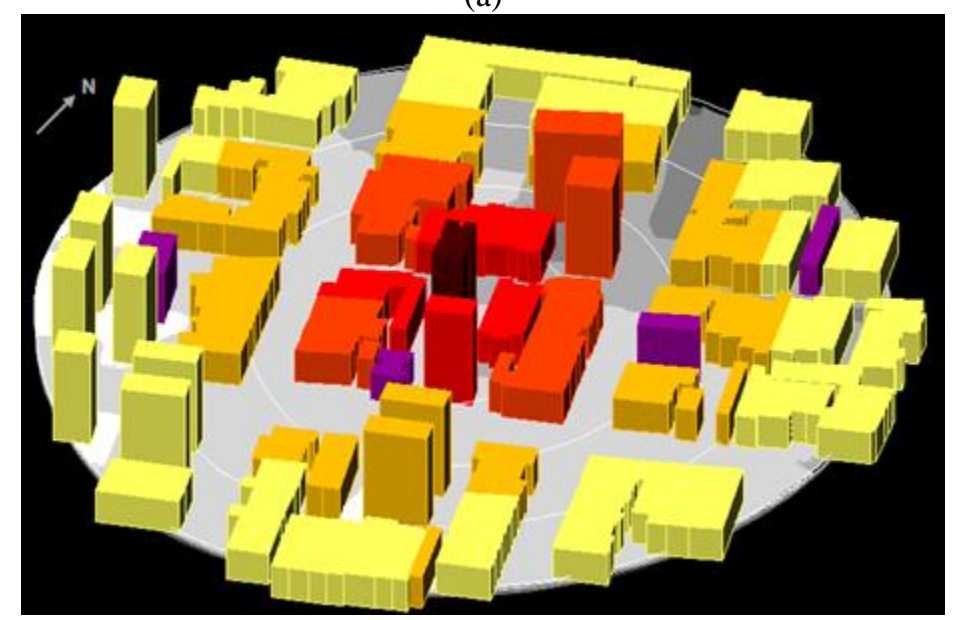

(b)

Figura 5 - (a) Cenário urbano real e (b) máximo de ocupação pelo plano diretor vigente

\section{Cenário real}

Os valores obtidos para os parâmetros FLDV nas edificações analisadas aumentam em direção aos pavimentos superiores em função da diminuição da obstrução. Esse fenômeno não é verificado para os valores de RP, pois estes variam de sinal e magnitude, de acordo com o horário e mês correspondente. 
Os impactos foram neutros, tanto na avaliação dos tipos de impactos quanto em relação à suscetibilidade, em todos os pontos dos quatro edifícios e para os dois parâmetros analisados no cenário urbano real. Isso se deve ao fato de a vizinhança ser pouco obstrutiva, fazendo com que o OI não seja tão impactante. Do contrário, com a vizinhança bastante obstrutiva, o OI poderia ser a obstrução necessária para resultar no impacto negativo.

Além da análise dos tipos de impactos, realizou-se a avaliação da redução dos parâmetros de desempenho verificados na situação anterior e posterior ao OI. As maiores reduções de FLDV por pavimento foram verificadas no edifício 1 , obtendo-se uma média de $20 \%$ para a fachada NO (Figura 6a). Para os valores de RP, as maiores reduções no balanço anual verificadas ocorreram na fachada SO do edifício 2 (Figura 6b). Essas reduções atingiram a média de $12 \%$ para todos os pavimentos. Os demais valores dos outros edifícios sofreram um decréscimo gradual, proporcional a seu distanciamento em relação ao OI, decorrente da diminuição da visibilidade dele.

Além da análise de redução dos parâmetros, realizou-se a verificação da porcentagem de contribuição da JCP - parâmetro complementar no FLDV total para cada ponto. Em geral, todos os valores ficaram próximos a 50\%. Esse valor demonstra uma participação efetiva dessa porção do céu, que possui apenas $1 / 3$ da área da meia abóbada no resultado final do FLDV.

Ainda em relação à contribuição da JCP, verificaram-se algumas tendências nos gráficos relacionados com os pavimentos dos edifícios (Figura 7). A tendência à linearidade na porcentagem de contribuição no FLDV contido na JCP ocorre quando a obstrução da vizinhança não se sobrepõe à JCP (delimitada em preto), como pode ser verificado no exemplo da Figura 7a. Soma-se a isso o fato de que o OI também reduz sua obstrução na JCP, fazendo com que a contribuição dessa área possua uma tendência linear entre os pavimentos. $\mathrm{O}$ comportamento decrescente em direção ao último pavimento também foi constatado (Figura 7b). Nesse caso, a JCP praticamente não é obstruída pela vizinhança, e essa obstrução diminui em direção ao último pavimento. Portanto, o resultando da contribuição é menor à medida que a área da JCP aumenta. O comportamento misto nos pavimentos - linear e decrescente -, em decorrência dessas razões, também foi verificado numa mesma edificação (observar máscaras no exemplo Figura 7c). Nos pavimentos mais baixos, este foi decrescente, e nos mais altos, linear.

\section{Cenário para ocupação prevista}

Após a análise do cenário real, modelou-se a ocupação máxima prevista pelo plano diretor vigente, que estabelece para a área a altura de $18 \mathrm{~m}$ ou $52 \mathrm{~m}$, dependendo do porte do terreno (Figura 5b). O objetivo dessa etapa foi avaliar os impactos sofridos pelas mesmas quatro edificações. Novamente, o impacto sofrido foi neutro, entretanto algumas edificações apresentaram, nas situações anterior e posterior ao OI, valores abaixo do mínimo, em detrimento do aumento das obstruções (Figura 8). As fachadas SE das edificações 2 e 4 apresentaram valores abaixo de $10 \%$ para o FLDV (Figuras 8a e 8c). Já a fachada NO da edificação 2 e a SO da edificação 4 apresentaram valores abaixo da média de 1,5 hora de sol no inverno (Figuras 8b e 8d).

\section{Considerações finais}

O objetivo desta pesquisa foi desenvolver um método para a avaliação dos impactos de novas edificações em vizinhanças urbanas com relação ao acesso às condições mínimas de insolação e iluminação natural. Nesse sentido, constatou-se que a maioria dos estudos de impacto de vizinhança brasileiros relatados não são adequados, seja pela utilização de técnicas limitadas, seja pela ausência de parâmetros consistentes. Quanto aos estudos internacionais, essa constatação não foi verificada. Entretanto, os métodos são adaptados à realidade local. A principal diferença em relação ao Brasil se dá em relação à insolação, que nem sempre é requerida em algumas regiões ou épocas do ano. $\mathrm{Na}$ literatura específica da área não existem métodos específicos para a avaliação de impactos, todavia se encontram parâmetros e técnicas adequados para a avaliação da iluminação natural e insolação passíveis de adaptações para as particularidades dos estudos de impacto de vizinhança.

Considera-se válido o esforço expendido nessa direção, pois ao quadro das antigas questões do planejamento urbano em relação ao acesso desses recursos naturais e à necessidade pertinente da utilização de recursos energéticos renováveis somam-se os novos desafios relacionados ao Estatuto da Cidade, visando regular o uso da propriedade urbana em prol do bem coletivo.

A respeito das estratégias propostas na metodologia, acredita-se que o desenvolvimento de um método integrado para a avaliação dos impactos, aliado a uma ferramenta computacional, seja fundamental. A utilização de técnicas de representação da visibilidade/obstrução da abóbada celeste, associada à disponibilidade de luz natural 
na fachada (FLDV) combinada à JCP e à radiação ponderada, promove a visualização dos resultados para a conferência da iluminação natural e insolação de maneira unificada. A obtenção de planilhas contendo os dados desses parâmetros integrados por meio das simulações computacionais operacionaliza a verificação dos impactos na forma de gráficos, conforme apresentado neste artigo.

\section{Ed.1 - Fachada NO}

Ed.2 - Fachada SO

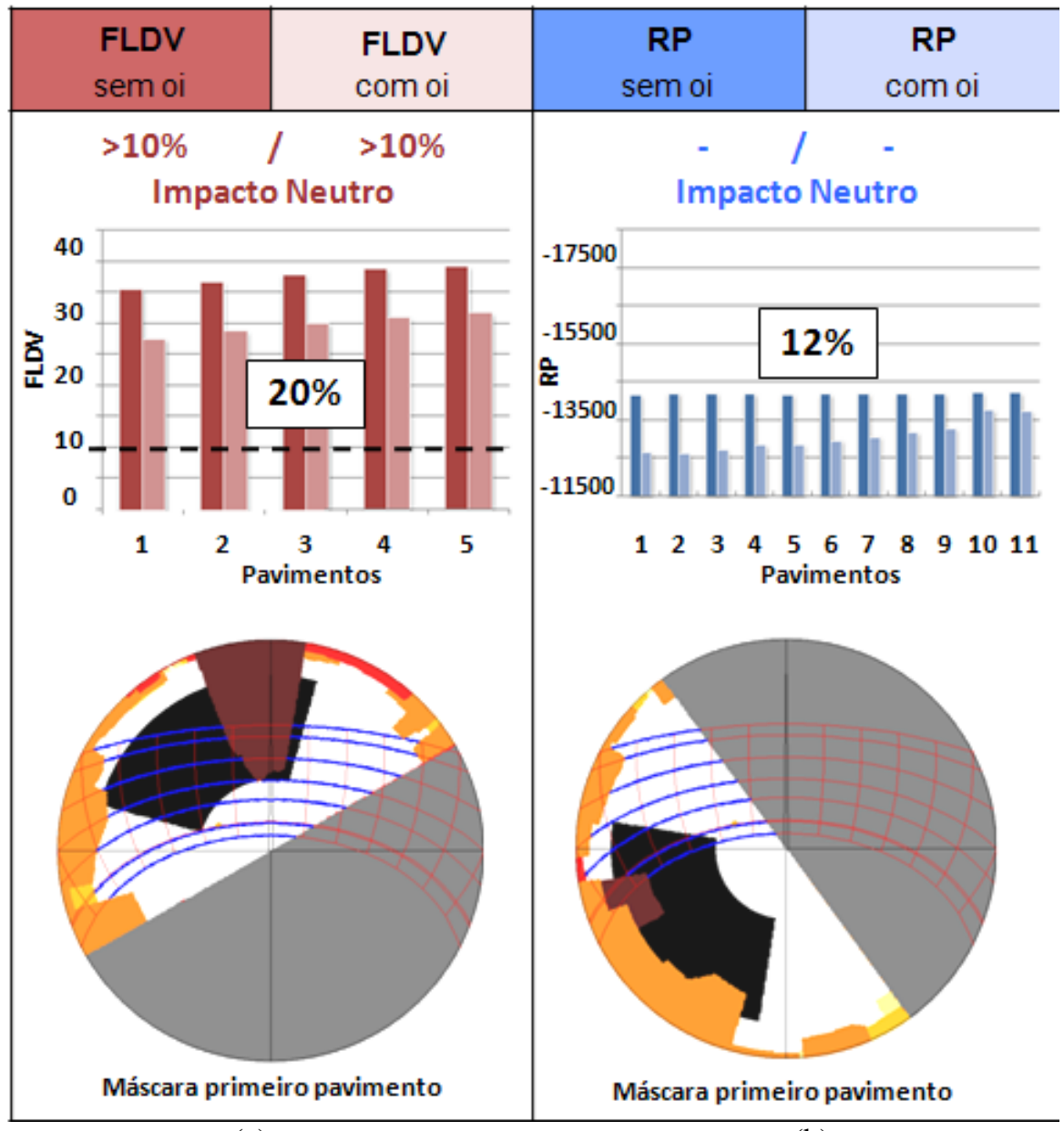

(a)

(b)

Figura 6 - (a) Maiores diferenças encontradas nas fachadas dos edifícios para FLDV e (b) RP e (c) valores mais próximos do mínimo para horas de sol nas situações anteriores e posteriores ao Ol 


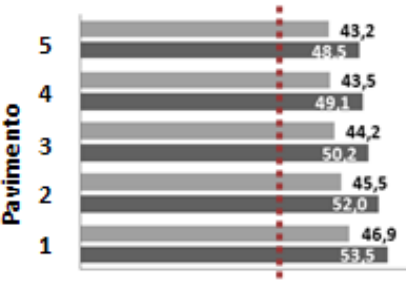

$0 \quad 20 \quad 40 \quad 60$

\% de contribuição da JCP no FLDV

= Com Ol $=$ Sem Ol

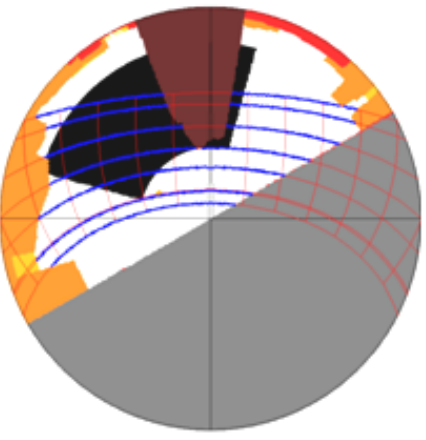

Máscara primeiro pavimento

(a)

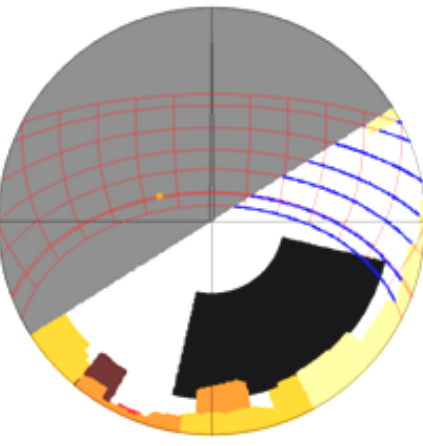

Máscara primeiro pavimento

(b)

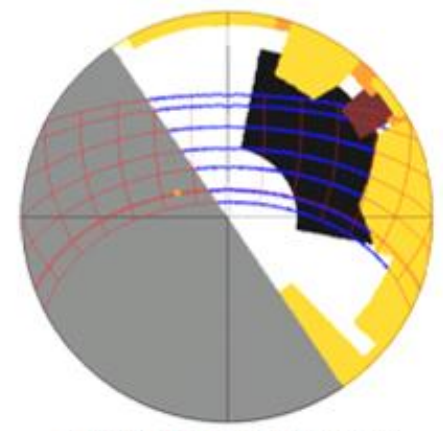

Máscara primeiro pavimento

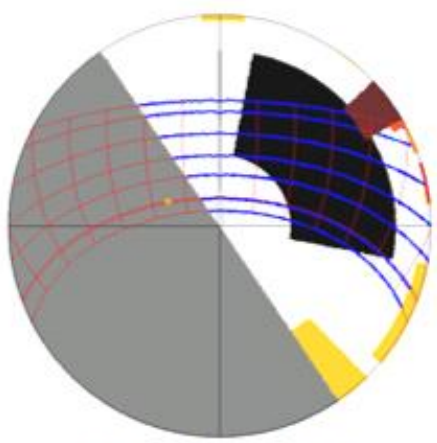

Máscara sexto pavimento

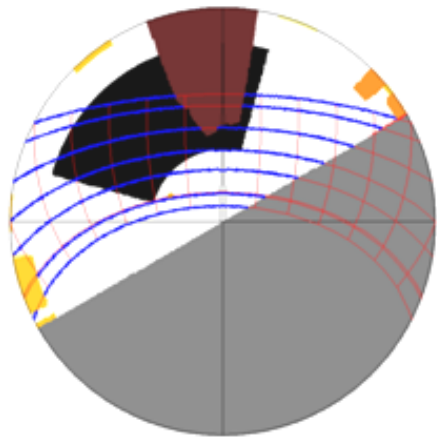

Máscara quinto pavimento

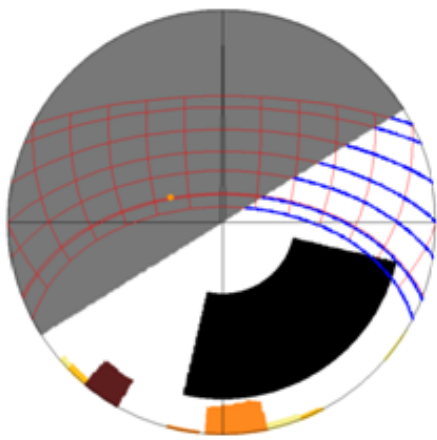

Máscara quinto pavimento

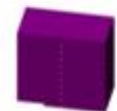

Edificio 3 - NE

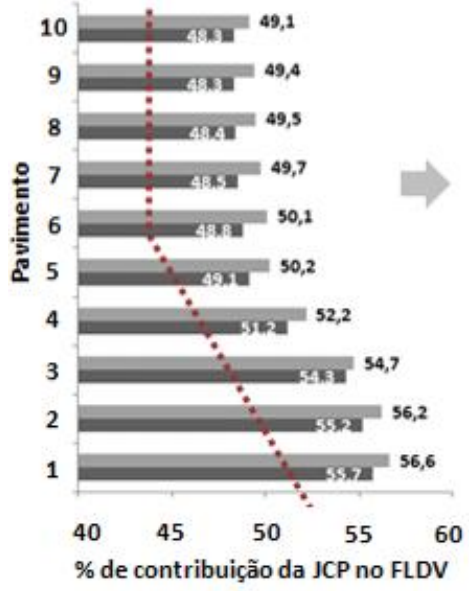

(c)

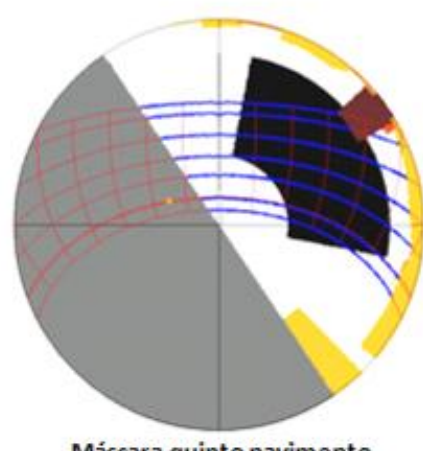

Máscara quinto pavimento

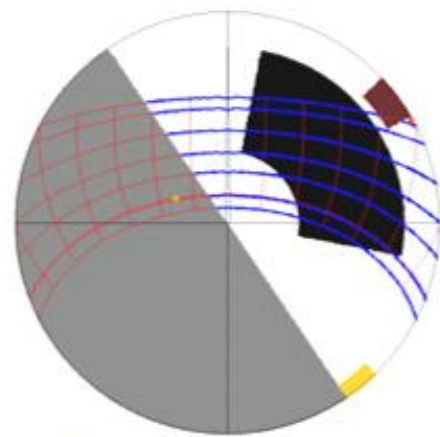

Máscara décimo pavimento

Figura 7 - Diferentes comportamentos verificados nos valores de contribuição da JCP no FLDV nos pavimentos das edificações: (a) linear, (b) decrescente e (c) misto - decrescente e linear 

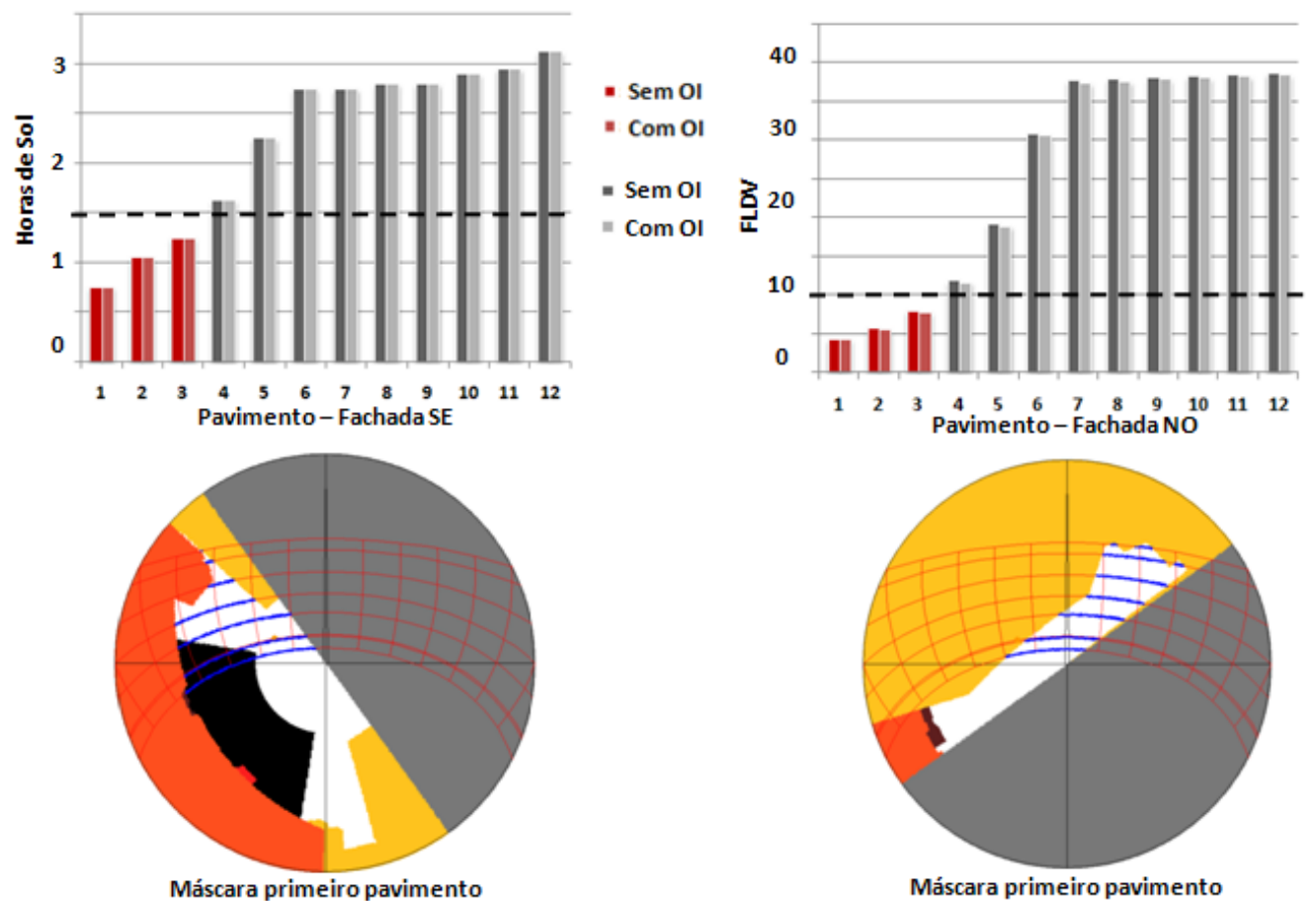

(a)

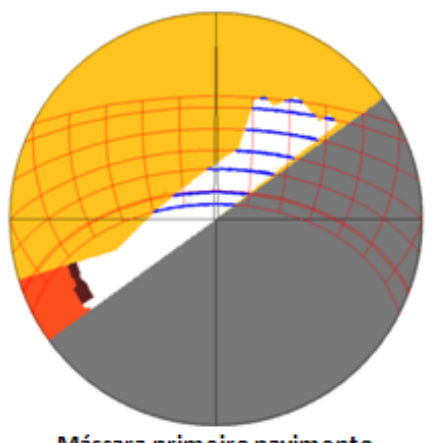

Máscara primeiro pavimento

(b)

Edifício 4

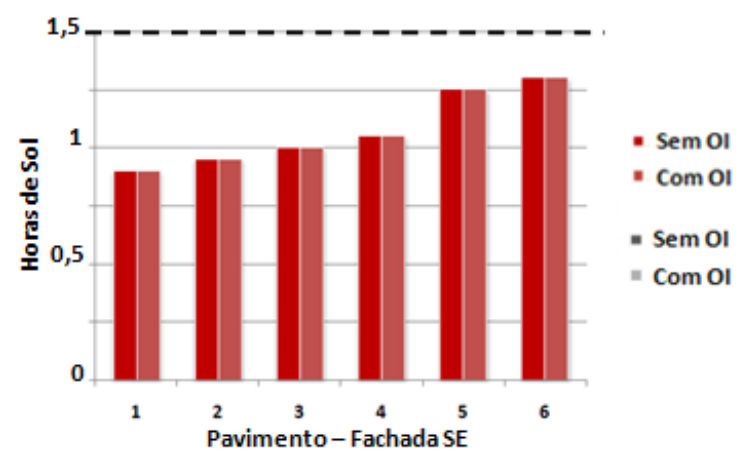

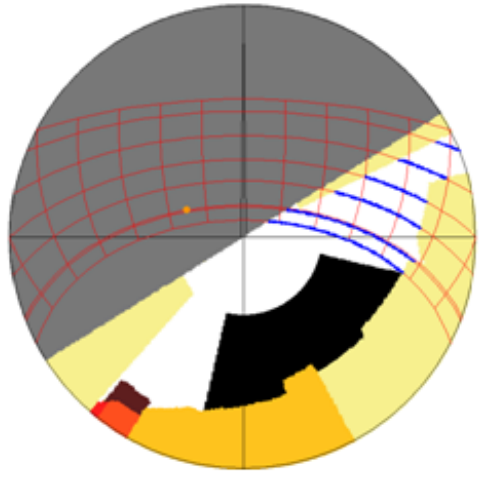

Máscara primeiro pavimento

(c)
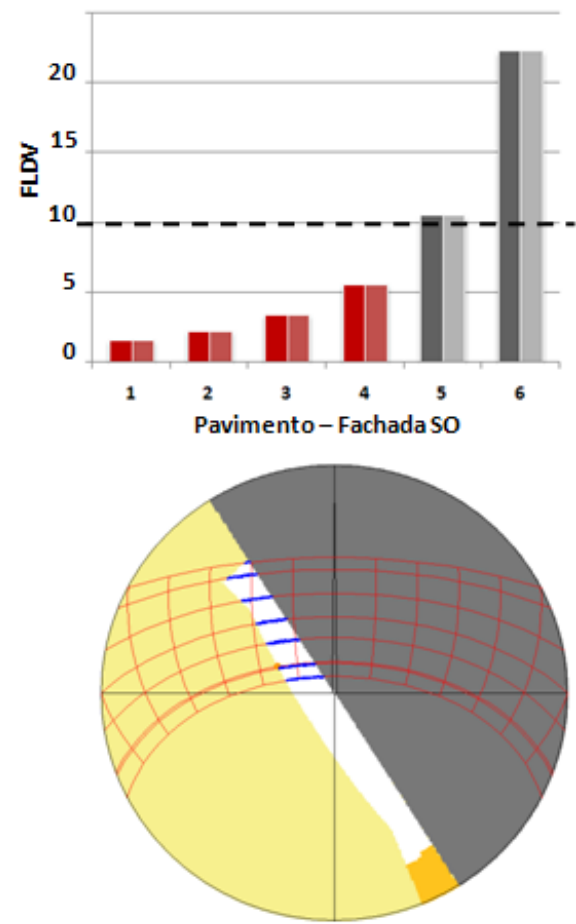

Máscara primeiro pavimento

(d)

Figura 8 - Edificações e suas fachadas que apresentaram impactos neutros, porém com valores abaixo do mínimo requerido nas situações anterior e posterior ao objeto de impacto 


\section{Referências}

ASSOCIAÇÃO BRASILEIRA DE NORMAS TÉCNICAS (ABNT). NBR 15220-3: desempenho térmico de edificações: parte 3: zoneamento bioclimático brasileiro e diretrizes construtivas para habitações unifamiliares de interesse social. Rio de Janeiro, 2005.

ALUCCI, M. P. (Org.). Implantação de Conjuntos Habitacionais: recomendações para adequação climática e acústica. São Paulo: IPT, 1986.

ARoztegui, J. M. Método para Projeto e Avaliação de Pára-Sóis Externos, visando à Otimização do seu Desempenho Térmico para um Clima Dado. Porto Alegre: Curso de PósGraduação em Engenharia Civil, Universidade Federal do Rio Grande do Sul, 1980. (Caderno Técnico, CT 17/80).

BRASIL. Lei no 10.257, de 10 de julho de 2001. Regulamenta os arts. 182 e 183 da Constituição Federal, estabelece diretrizes gerais da política urbana e dá outras providências. Brasília, DF, 2001.

BRASIL. Ministério Público Federal. Informação Técnica $n^{\circ}$ 156/08 - $4^{\text {a }}$ CCR. Estudo de Impacto de Vizinhança - EIV: descrição, aplicabilidade, diferenças entre EIV e EIA/RIMA. Brasília, DF, 2008. Disponível em:

<http://4ccr.pgr.mpf.gov.br/institucional/gruposde-trabalho/gt-zona-costeira/docs-zonacosteira/IT_156-08_EIV.pdf >. Acesso em: 15 out. 2008.

CAPELUTO, I. G. et al. Solar Rights in the Design of Urban Spaces. In: INTERNATIONAL CONFERENCE ON PASSIVE AND LOW ENERGY ARCHITECTURE, 23., 2006, Geneva. Proceedings... Geneva: PLEA, 2006.

CHENG, V. et al. Urban Form, Density and Solar Potential. In: INTERNATIONAL CONFERENCE ON PASSIVE AND LOW ENERGY

ARCHITECTURE, 23., 2006, Geneva. Proceedings... Geneva: PLEA, 2006.

CLARO, A. Modelo Vetorial Esférico para Radiosidade Aplicado à Iluminação Natural. 1998. 173 f. Tese (Doutorado em Engenharia de Produção) - Centro Tecnológico, Universidade Federal de Santa Catarina, Florianópolis, 1998.

DRIVER, J. Stroke-on-Trent City Centre Environmental Statement: daylight, sunlight and overshadowing. London, 2008. Available from: <http://www.planning.stoke.gov.uk/Documents/73 0_17.pdf>. Access at: 05 Jan. 2010.
HER MAJESTY'S STATIONERY OFFICE (HMSO). Sunlight and Daylight: planning criteria and design of buildings. London: Department of The Environment Welsh Office, 1982.

HOPKINSON, R. G.; PETHERBRIDGE, P.; LONGMORE, J. Daylighting. London: Heinemann, 1966.

KNOWLES, R. L. Sun Rhythm Form. Cambridge: MIT, 1981.

LEDER, S. M. Ocupação Urbana e Luz Natural: proposta de parâmetro de controle da obstrução do céu para garantia da disponibilidade de luz natural. 2007. 240 f. Tese (Doutorado em Engenharia Civil) - Centro Tecnológico, Universidade Federal de Santa Catarina, Florianópolis, 2007.

LINDBERG, F. Urban Geometry and Temperature Variations. In: INTERNATIONAL CONFERENCE ON URBAN CLIMATE, 15., 2003, Lodz, Poland. Proceedings... Lodz: ICUC, 2003.

LITTLEFAIR, P. Site Layout Planning for Daylight and Sunlight: a guide to good practice. Garston: Building Research Establishment Report, 1991.

MORETTI, R. S. Critérios de Urbanização para Empreendimentos Habitacionais. 1993. $193 \mathrm{f}$.

Tese (Doutorado) - Escola Politécnica, Universidade de São Paulo, São Paulo, 1993.

NE'EMAN, E.; LIGHT, W. Availability of Sunshine. BRE Current Paper CP 75:75, 1975.

NE'EMAN, E.; HOPKINSON, R. G. Sunlight in Buildings: requirements and recommendations. Wien, 1976. (CIE Publication, 36).

NG, E. A New Method for Daylight Design of High-Density Cities: experiences from Hong Kong. In: INTERNATIONAL CONFERENCE ON PASSIVE AND LOW ENERGY ARCHITECTURE, 20., 2003, Santiago de Chile. Proceedings... Santiago de Chile: PLEA, 2003. p. D-6.

NG, E. A Study of the Relationship between Daylight Performance and Height Difference of Buildings in High Density Cities using Computational Simulation. In: INTERNATIONAL BUILDING PERFORMANCE SIMULATION CONFERENCE, 9., 2005, Montreal. Proceedings... Montreal: IBPSA, 2005. p. 847852. 
PEREIRA, F. O. R.; SILVA, C. A. N.;

TURKIENIKZ, B. A Methodology for Sunlight Urban Planning: a computer-based solar and sky vault obstruction analysis. Solar Energy, London, v. 70, n. 3, p. 217-226, 2001.

ROBBINS, C. L. Daylighting: design and analysis. New York: Van Nostrand Reinhold, 1986.

OBOLENSKY, N. V.; KORZIN O. A. Insolation and Sun Control in the Field of Construction: the progressive ways of their normalisation and regulation. In: CIB SYMPOSIUM IN BUILDING CLIMATOLOGY, 1982, Moscow. Proceedings... Moscow: CIB, 1982. p. 498-520.
TREGENZA, P. Sunlight, Skylight and Electric Light. In: ENCONTRO NACIONAL DE CONFORTO NO AMBIENTE CONSTRUIIDO, 2., 1993, Florianópolis. Anais... Porto Alegre: ANTAC, 1993. 1 CD-ROM.

TREGENZA, P. Daylight criteria and a simple graphical tool. [S.1.: S.n.], 2001. Notas não publicadas.

\section{Agradecimentos}

À Capes, pelo suporte financeiro, na forma de bolsa de estudos. 